\title{
Loud noise potentiates conditioned fear in extinction using a CER (lick suppression) paradigm in rats
}

\author{
MORRIE BAUM \\ Rensselaer Polytechnic Institute, Troy, New York \\ and \\ W. J. JACOBS \\ University of Lethbridge, Lethbridge, Alberta, Canada
}

Two groups of rats were given CER conditioning and extinction, using the Jacobs, Buttrick, and Kennedy (1988) methodology. For one group, loud noise was introduced concurrently with the light CS in extinction. Loud noise was found to potentiate the CER in lick suppression. On a final test day of extinction, both groups received CS-alone presentations. No evidence of protection from extinction by the noise was found. The results were related to other effects of noise on extinction in aversive paradigms.

Previous research, using the automated, one-way avoidance apparatus described by Baum (1965), found that loud noise, introduced for the first time in extinction and concurrent with the CS-UCS interval, potentiated or increased avoidance responding in extinction (Baum, Jaffe, \& Leclerc, 1971, Experiment 2, Group B-CS). Because instrumental avoidance responding is often assumed to be mediated by a state of Pavlovian-conditioned fear (e.g., see Rescorla \& Solomon, 1967), loud noise introduced for the first time in extinction should also potentiate fear as measured by the CER (conditioned emotional response) procedure. In the present study, we tested this prediction, using the lick-suppression CER procedure described by Jacobs, Buttrick, and Kennedy (1988).

\section{METHOD}

\section{Subjects}

Thirty-two locally bred, experimentally naive, male Long-Evans rats were used. The rats were individually housed and maintained on a reversed 12:12-h day:night cycle with free access to food and water before the beginning of the experiment. The training and conditioning sessions occurred during the night portion of the day:night cycle. The rats were approximately 60 days of age at the beginning of the experiment.

\section{Apparatus}

Eight experimental chambers $(25 \times 30 \times 18 \mathrm{~cm})$ were used (see Jacobs et al., 1988, for a complete description). Three 19-gauge stainless steel tubes were soldered side by side to produce a single licking tube with three apertures. Each of the three tubes was connected to its own reservoir through a solenoid valve. This arrangement allowed up to three separate solutions to be delivered to the licking tube by the timed operation of one or more of the solenoid valves. The licking tube protruded

This research was supported by an NSERC of Canada University Fellowship (U0262) awarded to W. J. Jacobs. Address reprint requests to W. J. Jacobs, Department of Psychology, 4401 University Drive, University of Lethbridge, Lethbridge, Alberta T1K 3M4, Canada. into a hole centered on one wall of each chamber just above the grid floor. The rat contacted the tube by extending its tongue into the hole. In this experiment, a $0.1 \%$ saccharin solution was delivered to the licking tube. The other valves remained inoperative.

A 28-V houselight was centered on the front wall of the chamber, $10.7 \mathrm{~cm}$ from the grid floor. A speaker was centrally mounted on the ceiling of the chamber. The grid floor and licking tube were attached to a house-built lickometer/shock circuit, such that the lick tube was electrically isolated when scrambled shock was delivered to the grid floor.

A computer located in an adjacent room regulated the experimental conditions and data collection.

\section{Procedure}

Each rat was given $48 \mathrm{~h}$ of continuous exposure to a $0.1 \%$ saccharin solution in its home cage 1 week before the beginning of the experiment. This exposure eliminated neophobia to saccharin.

Deprivation. Twenty-four hours before the beginning of the experiment, the rats were deprived of water. The rats received $30 \mathrm{~min}$ of free access to water immediately following each experimental session.

Training (Day 1). On the first experimental day, the rats were placed individually in the experimental chamber and trained to lick for a 0.25 -sec (approximately $0.01 \mathrm{cc}$ ) access to a $0.1 \%$ saccharin solution. Licking produced access to the solution on a VR-3 schedule of reinforcement for the first 20 presentations, a VR-5 for the next 20, and a VR-10 for the remainder of the experimental session. Each experimental session was 20 min long.

Conditioning (Day 2). Conditioning occurred on the second experimental day. The rats were placed individually in their respective experimental chambers and were presented with six 30 -sec presentations of the houselight on a VT-5-min schedule. Each presentation of the houselight was followed immediately by a $0.75-\mathrm{sec}, 0.5-\mathrm{mA}$ scrambled electric shock.

Extinction (Days 3-8). The rats were trained to lick as they were on the training day. After each rat had achieved the VR-10 schedule, six 30-sec presentations of a stimulus (illumination of the houselight for the first group and a compound stimulus consisting of illumination of the houselight/white noise for the second group) were given on a VI-190-sec schedule. The rats were required to lick five times during the 30 -sec interval that immediately preceded each stimulus presentation. If fewer than five licks occurred during that interval, then it was reset. This continued until the rat met the response criterion. The number of licks that occurred during the 30 -sec intervals immediately before and during presentations of the stimulus was recorded. 


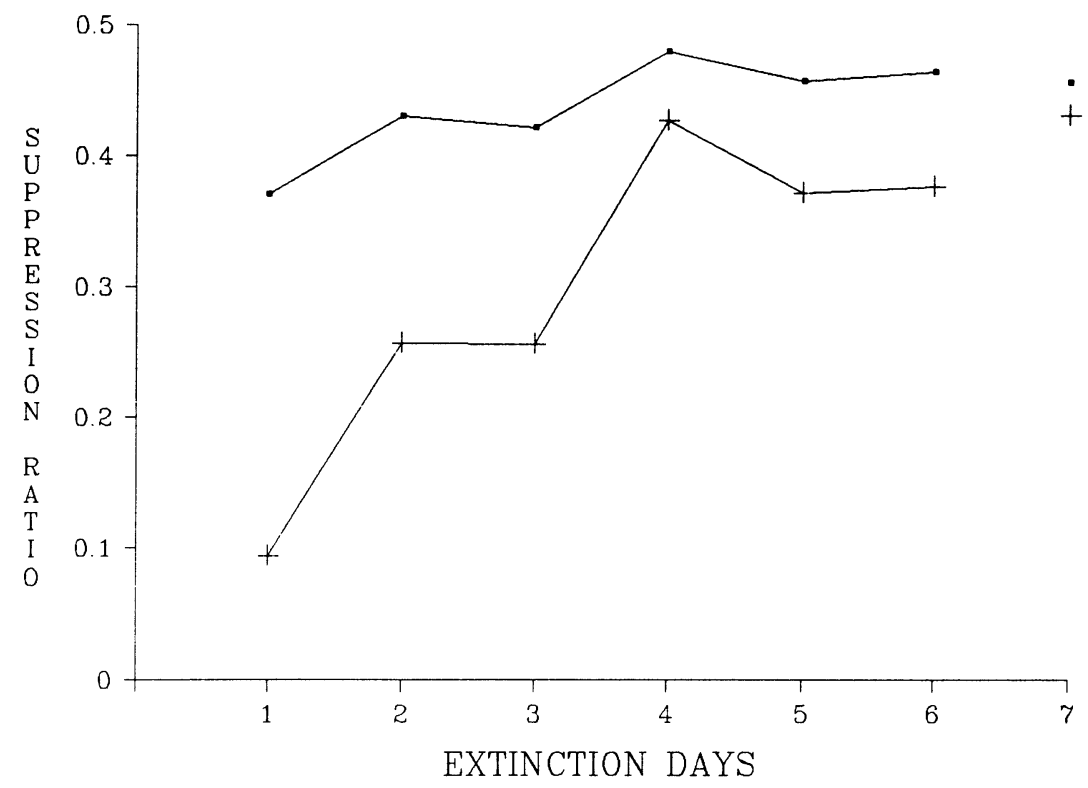

Figure 1. The daily suppression ratio during CER (lick suppression) extinction plotted for the two groups. One group (dots) received simple extinction trials (30-sec illumination of the houselight), the other (crosses) received a loud noise in compound with the conditioned stimulus (30-sec illumination of the houselight) for 6 days of extinction. On Day 7, a test day, the rats in both groups received simple extinction (six 30-sec presentations of illumination of the houselight).

Thus, each of the 16 rats in the first group received six 30 -sec illuminations of the houselight during each of the six extinction sessions. Each of the 16 rats in the second group received six $30-\sec$ presentations of illumination of the houselight and a concurrent $30-\mathrm{sec}$ sounding of a 75-dB white noise during each of the six extinction sessions.

Test (Day 9). The rats were trained to lick as they were on the training day. After achieving the VR-10 schedule, both groups received 30 -sec presentations of the illumination of the houselight as described for the first group during the extinction phase of the experiment.

\section{RESULTS}

Suppression ratios were calculated in the manner described by Annau and Kamin (1961). The ratio yields a value of 0.50 if the rate of licking does not change in the presence of the conditional stimulus, and a value below 0.50 if the rate of licking decreases in its presence. For each day of extinction, a daily suppression ratio was calculated by combining the total number of licks in the 180 -sec pre-CS period versus the number of licks in the $180 \mathrm{sec}$ of the CS. These results are depicted in Figure 1. Comparison of the two groups (light CS versus noise + light CS) was done by means of the nonparametric MannWhitney U-test.

As is evident from Figure 1, the rats in the light + noise group displayed significantly greater lick suppression than did the light (CS-alone) group through extinction (e.g., on Day 1 of extinction, $U=27.5, p<.002$; on Day 2 , $U=10.5, p<.002)$. Even though the difference tended to diminish late in extinction, it remained significant (e.g., on Day $6, U=57, p<.02$ ). On Day 7 of extinction (Day 9 of the procedure), both groups received presentations of a $30-\mathrm{sec}$ illumination of the houselight. The mean daily suppression ratios for the first and second groups did not differ significantly on this day $(U=95$, $p>.10)$.

\section{DISCUSSION}

The present study shows that loud noise, introduced in extinction concurrently with the conditioned stimulus, potentiates Pavlovian conditioned fear. This suggests that the increased persistence of instrumental avoidance responding in extinction also produced by noise (Baum et al., 1971, Experiment 2, Group B-CS) is mediated by intensified conditional fear in a way compatible with the two-process theory of avoidance (Rescorla \& Solomon, 1967). It has also been shown that such noise can produce, at least to some extent, a recovery from extinction of an avoidance response (Baum, 1971).

The analysis presented above, however, fails to apply to the case of response prevention (flooding), a Pavlovian-like procedure that is interpolated between avoidance acquisition and extinction (reviewed by Baum, 1970). Here, loud noise introduced only during the period of response prevention increases the efficacy of the procedure in hastening response extinction (Baum \& Gordon, 1970; Baum, Pereira, \& Leclerc, 1985). The latter effect remains poorly understood. Furthermore, the presence of this effect serves to underline the fact that twoprocess theory does not completely account for the effects of noise on extinction of aversively motivated responding.

In this study, fear of the conditioned stimulus on Day 7 of extinction (Day 9 of the procedure) was the same for both groups (virtually no suppression), indicating that an extinction history with noise accompaniment in no way protected the conditioned stimulus from the effects of extinction. That is, there was no evidence of the protection-fromextinction effect (LoLordo \& Rescorla, 1966; Soltysik \& Wolfe, 1980).

\section{REFERENCES}

AnNaU, Z., \& Kamin, L. J. (1961). The conditioned emotional response as a function of intensity in rats. Journal of Comparative \& Physiological Psychology, 54, 428-432. 
BAUM, M. (1965). An automated apparatus for the avoidance training of rats. Psychological Reports, 18, 59-64.

BAUM, M. (1970). Extinction of avoidance responding through response prevention (flooding). Psychological Bulletin, 74, 276-284.

BAUM, M. (1971). Extinction of an avoidance response in rats via response prevention (flooding): A test for residual fear. Psychological Reports, 28, 203-208.

BAUM, M., \& GoRDON, A. (1970). Effects of a loud buzzer applied during response prevention (flooding) in rats. Behaviour Research \& Therapy, 8, 287-292.

BAUM, M., JAFFe, P. G., \& LeCLerC, R. (1971). The effect of a loud buzzer upon the acquisition and extinction of a simple avoidance response in rats. Canadian Journal of Psychology, 25, 24-32.

Baum, M., Pereira, J., \& LeClerc, R. (1985). Extinction of avoidance responding in rats: The noise-intensity parameter in noise-facilitation of flooding. Canadian Journal of Psychology, 39, 529-535.
JaCoBs, W. J., Buttrick, M., \& KenNedy, D. (1988). A rapid and sensitive method for measuring the conditioned emotional response: II. On-the-baseline excitatory conditioning and extinction. Pavlovian Journal of Biological Science, 23, 29-34.

LoLordo, V. M., \& Rescorla, R. A. (1966). Protection of the feareliciting capacity of a stimulus from extinction. Acta Biologiae Experimentalis, 26, 251-258.

Rescorla, R. A., \& Solomon, R. L. (1967). Two-process learning theory: Relationships between Pavlovian conditioning and instrumental learning. Psychological Review, 74, 151-182.

SoltysiK, S., \& Wolfe, G. (1980). Protection from extinction by a conditioned inhibitor. Acta Neurobiologiae Experimentalis, 40, 291-311.

(Manuscript received March 22, 1989.) 